\title{
La igualdad en la Constitución Española
}

\author{
Magdalena González Jiménez*
}

\section{INTRODUCCIÓN}

El principio de igualdad ante la ley es una vieja aspiración del ser humano que fue recogida con entusiasmo por el movimiento constitucional del siglo XVIII que marcó el fin del Antiguo Régimen. Se convirtió en una de las principales reivindicaciones de los revolucionarios liberales, especialmente de los franceses, hasta el punto de que su proclamación forma parte de la divisa del Estado surgido de la Revolución francesa ("libertad, igualdad, fraternidad").

Entonces, la finalidad de la enunciación de este principio respondía a un objetivo muy concreto: acabar con la situación del Antiguo Régimen, rompiendo con el sistema corporativo y estamental basado en privilegios, característico de la historia europea hasta ese momento. Según se perteneciera a un estamento, corporación o gremio los derechos eran diferentes. El sentido igualitario de la Revolución, a fin de acabar con esos privilegios, llevó a la proclamación formal de la igualdad de todos los hombres ante la ley. Proclamación fundamental para la posterior construcción del Estado de Derecho, basado en la existencia de ciudadanos y no de súbditos, pues uno de los requisitos del mismo era la afirmación de la ley en su doble naturaleza de general y abstracta, que obliga a todos por igual. En la actualidad, la igualdad se configura como una noción más compleja y es objeto de reconocimiento en los distintos textos constitucionales nacionales e internacionales.

En la Constitución española es posible encontrar diferentes acepciones de la expresión "igualdad", lo que obliga a interrelacionar todas ellas. En primer lugar, el art. 1.1 de la Constitución española de 1978 consagra entre los valores superiores de su ordenamiento jurídico el de la igualdad. En este sentido, el Tribunal Constitucional ha manifestado que "la igualdad es un valor preeminente de nuestro ordenamiento jurídico, al que cabe colocar en un rango central, como demuestra el

* Prof. ${ }^{a}$ Doctora - Universidad de Castilla-La Mancha, Facultad de Derecho de Albacete - España. 
artículo 1.1 CE". Reconocer la igualdad como valor preeminente o superior supone reconocer su carácter de principio inspirador de todo el ordenamiento jurídico, sirviendo de criterio de interpretación e integración del mismo.

Como tal valor superior, la igualdad se concreta y desarrolla a lo largo de todo nuestro texto constitucional. Así, por ejemplo, en el art. 23.2 se reconoce el derecho de acceder en condiciones de igualdad a las funciones y cargos públicos; en el art. 31.1 se hace alusión a un sistema tributario justo inspirado en los principios de igualdad y progresividad; el art. 32.1 consagra el derecho del hombre y de la mujer a contraer matrimonio con plena igualdad jurídica; el art. 139.1 establece la igualdad de derechos y deberes de los españoles en cualquier territorio del Estado, etc.

Ahora bien, la igualdad tiene en nuestra Constitución dos dimensiones o desarrollos capitales, complementarios entre sí, que son el 9.2, que reconoce la igualdad real o material al decir que "corresponde a los poderes públicos promover las condiciones para que la libertad y la igualdad del individuo y de los grupos en que se integra sean reales y efectivas, remover los obstáculos que impiden o dificulten su plenitud y facilitar la participación de todos los ciudadanos en la vida política, económica, cultural y social"; y el artículo 14, que consagra la igualdad formal o jurídica cuando dispone que los españoles son iguales ante la ley, sin que pueda prevalecer discriminación alguna, susceptible también de recurso de amparo ante el Tribunal Constitucional (art. 53.2 CE).

\section{LA IGUALDAD FORMAL: EL PRINCIPIO GENÉRICO DE IGUALDAD ANTE LA LEY}

\section{CONSIDERACIÓN PRELIMINAR}

Del análisis de la jurisprudencia del Tribunal Constitucional español cabe mantener, como así lo ha entendido parte de la doctrina, que el art. 14 de la Constitución española establece dos mandatos diferentes, con efectos jurídicos distintos, en cada uno de sus dos incisos: en el primero: "Los españoles son iguales ante la ley (...)", dirigido a los poderes públicos, se consagraría el clásico principio de que las leyes, y derivativamente sus aplicaciones, deben considerar a los ciudadanos como iguales sin hacer entre ellos distinciones arbitrarias o irrazonables; en el segundo, en cambio, se impondría una prohibición mucho más taxativa y perentoria de "discriminación alguna por razón de nacimiento, raza, sexo, religión, opinión o cualquier otra condición o circunstancia personal o social".

No obstante, esta dicotomía no es perfecta, pues como señala RUIZ MIGUEL', "si en los casos extremos la distinción es clara y aun tajante, no deja de existir una zona de transición entre ambos que, naturalmente, es consecuencia de que cada uno de ellos es susceptible de graduación y no de una definición por simple negación del par opuesto". Centrémonos ahora en el que hemos calificado como principio genérico de igualdad ante la ley, dirigido a los poderes públicos ${ }^{2}$, que a su 
vez presenta dos manifestaciones, a las que podríamos denominar, respectivamente, principio de igualdad en la ley y principio de igualdad en la aplicación de la ley.

\section{TITULARIDAD}

El principio genérico de igualdad ante la ley se reconoce a las personas físicas y a las jurídico-privadas, pues, tal y como afirma el Tribunal Constitucional, el artículo 14 emplea el término "españoles" sin más distinciones. No obstante, el Alto Tribunal advierte que ello no implica una necesaria equiparación entre unas y otras. Al ser estas últimas una creación del Derecho, corresponde al ordenamiento jurídico delimitar su campo de actuación fijando los límites concretos y específicos, así como determinar, en su caso, si una concreta actividad puede ser desarrollada en un plano de igualdad tanto por personas físicas como jurídicas (SSTC 99/1983, 20/1985, 26/1985, 29/1986, 23/1989).

Distinto es el caso de las personas jurídico-públicas. Téngase en cuenta que ni el origen ni el sentido ni la estructura de los derechos fundamentales permiten fácilmente su extensión a los poderes públicos. Estos poseen potestades y competencias que están delimitadas por disposiciones legales y atienden a intereses públicos, por lo que difícilmente pueden ser titulares de derechos fundamentales que, como genuinos derechos subjetivos, atienden a intereses propios de los sujetos favorecidos por ellos. Existen pues importantes dificultades para reconocer la titularidad de derechos fundamentales a las entidades de derecho público, de forma que habrá de analizarse de manera concreta y singularizada cada supuesto, atendiendo a la específica naturaleza del derecho fundamental de que se trate. Por lo que respecta al principio de igualdad, el Tribunal Constitucional sólo ha admitido en ocasiones su lesión cuando se ha tratado de desigualdades «en la aplicación de la ley» y ello en base a su íntima conexión con el derecho a la tutela judicial efectiva: dado que un rasgo esencial del Estado de Derecho es el sometimiento de los poderes públicos a la jurisdicción, la situación de éstos frente a la misma no se ha considerado radicalmente diferente a la de los particulares y, por tanto, las mismas razones que justifican la viabilidad de la invocación del derecho a la tutela judicial efectiva por parte de los entes públicos han de aplicarse a los supuestos de desigualdad en la aplicación judicial de la ley en los que está en juego, no sólo el art. 14 CE, sino también, en todo caso, el art. 24 CE (SSTC 100/1993 y 239/2001).

Por otro lado, del tenor literal del artículo se desprende que el principio de igualdad se proclama en exclusiva para los "españoles". Ahora bien, la inexistencia de una declaración constitucional que proclame la igualdad de los extranjeros y españoles no es, sin embargo, argumento suficiente para estimar que la desigualdad de trato entre españoles y extranjeros sea siempre constitucionalmente admisible, porque el art. 14 no es el único precepto que debe ser contemplado a estos efectos. Junto a él hay que tener en cuenta otros sin los que resultaría imposible determinar la posición jurídica de los extranjeros en España, principalmente, el art. 13 de la 
Constitución, la Ley Orgánica 4/2000, de 11 de enero, de Derechos y Libertades de los Extranjeros en España y su Integración Social y lo dispuesto en los Tratados Internacionales ratificados por España. Y, en definitiva, según jurisprudencia del Tribunal Constitucional, debe darse una completa igualdad entre españoles y extranjeros respecto a aquellos derechos que son considerados imprescindibles para la garantía de la dignidad humana y que, por tanto, pertenecen a la persona en cuanto tal y no como ciudadano. Nos referimos a derechos como la vida, la integridad física y moral, la intimidad, la libertad ideológica, el derecho a la tutela judicial efectiva y el derecho instrumental a la asistencia jurídica gratuita, el derecho a la libertad y a la seguridad, y, como veremos inmediatamente después, el derecho a no ser discriminado por razón de nacimiento, raza, sexo, religión o cualquier otra condición o circunstancia personal o social (STC 236/2007, de 7 de noviembre).

\section{EL PRINCIPIO DE IGUALDAD EN LA LEY}

Principio de igualdad en la ley que mejor debiéramos llamar igualdad en la norma jurídica, puesto que se proyecta sobre la norma jurídica en abstracto, con independencia de su rango (SSTC 209/1987, 78/1990, 4/1991 y 69/1992, entre otras).

El principio de igualdad en la ley se refiere al contenido de la norma, actuando como un auténtico límite para su creador en el sentido de que no pueden establecerse distinciones artificiosas o arbitrarias entre supuestos de hecho iguales o cuyas diferencias reales, en caso de existir, carezcan de relevancia desde el punto de vista de la finalidad de la misma. Por tanto, el principio de igualdad en la ley no prohíbe toda diferencia de trato, sino tan solo la diferenciación arbitraria. En concreto, para que un trato desigual sea constitutivo de una diferenciación admisible, el TC requiere determinadas condiciones (establecidas, entre otras, en las siguientes sentencias: 22/1981, 10/1983, 6/1984, 23/1984, 99/1984, 13/1986, 42/1986, 166/1986, 19/1987, 39/1987, 129/1987, 162/1987, 51/1988, 67/1988, 260/1988, 227/1988, 25/1989, 73/1989, 68/1990, 76/1990, 110/1990; 50/1991, 64/1991, 87/1991, 114/1992):

- En primer lugar, la desigualdad de los supuestos de hecho. Precisamente será tal desigualdad la que permitirá o requerirá un trato también diferente. Como reiteradamente ha señalado el Tribunal Constitucional "no puede darse violación del principio de igualdad entre quienes se hallan en situaciones diferentes" (STC 26/1987). En otras palabras, el principio de igualdad solo se vulnera cuando se trata desigualmente a los iguales. La identidad de las situaciones fácticas constituye, por tanto, el presupuesto ineludible para la aplicación del principio de igualdad, correspondiendo a quien lo invoca la carga de ofrecer un término de comparación válido -tertium comparationis- en relación al cual deba predicarse la pretendida igualdad ${ }^{3}$. 
- En segundo lugar, para decidir si hay o no vulneración de este principio hay que atender a la finalidad de la medida diferenciadora. En primer lugar, porque los ciudadanos o los grupos no pueden ser tratados diferentemente de forma gratuita. Para que la diferencia de trato sea legítima ha de tener una finalidad. Además, no basta con una finalidad cualquiera, sino que debe tratarse de una finalidad constitucionalmente admisible, lo que, como señala GARCÍA MORILLO ${ }^{4}$, no implica que necesariamente deba consistir en un bien o valor constitucional, o que deba estar constitucionalmente recogida o consagrada; basta con que no colisione con el sistema de valores constitucionalmente consagrado.

- Además, debe darse una estructura interna de congruencia, de conexión efectiva, entre el trato diferenciador, el supuesto de hecho que lo fundamenta y la finalidad perseguida (STC 114/1987).

- También es preciso que la relación entre estos tres elementos esté caracterizada por la proporcionalidad. En palabras del Tribunal Constitucional, el principio de igualdad también exige que la diferencia de trato "supere un juicio de proporcionalidad en sede constitucional sobre la relación existente entre la medida adoptada, el resultado producido y la finalidad pretendida por el legislador" (STC 76/1990, FJ 4)

\section{EL PRINCIPIO DE IGUALDAD EN LA APLICACIÓN DE LA LEY}

Principio que, más correctamente, debería denominarse principio de igualdad en la aplicación de la norma jurídica, y que opera tanto sobre los órganos judiciales como sobre los administrativos. Comenzaremos por exponer las implicaciones del mismo sobre los primeros, para terminar con una breve alusión a sus peculiaridades cuando se proyecta sobre los órganos administrativos.

Para apreciar vulneración del principio de igualdad en las resoluciones judiciales el Tribunal Constitucional exige también, como en el caso anterior, la identidad de las situaciones fácticas y la aportación de un término de comparación, pero con el añadido de que el órgano jurisdiccional que resuelva ambos casos ha de ser el mismo, pues el principio de igualdad en la aplicación de la ley tiene necesariamente que conectarse con el principio de independencia en el ejercicio de la función jurisdiccional reconocido a cada uno de los Jueces y Tribunales que integran el Poder Judicial por el art. 117.1 CE (SSTC 2/1983, 39/1984, 78/1984, 36/1985, 55/1985, 41/1986, 125/1986, 101/1987, 105/1987, 124/1988, 260/1988, 146/1990, 166/1990, 105/1991, 237/1991, 85/1992, 86/1992 у 218/1992, entre otras). No obstante, el Alto Tribunal no ha llegado tan lejos como para restringir tal identidad incluso a los mismos titulares personales, estimando que es órgano judicial idéntico el juzgado o el tribunal que, con independencia de los cambios en las personas que lo ocupen, tiene jurisdicción en un determinado territorio y que, en su caso, aun dentro del mismo territorio, forma además colegio 
independiente. Por tanto, de acuerdo con tal criterio, las diversas secciones de una Audiencia Provincial, o las distintas Salas del Tribunal Supremo, son órganos jurisdiccionales distintos entre sí (ATC 233/1985 y SSTC 200/1990, 134/1991, 183/1991 y 86/1992). En definitiva, esto explica que en materias en las que no existe recurso ante el Tribunal Supremo, como órgano encargado de unificar los criterios de interpretación judicial de las normas jurídicas, pueda haber sentencias opuestas en los mismos asuntos.

Ahora bien, nada impide a los órganos judiciales proceder a rectificar su propia y precedente interpretación de la norma siempre y cuando tal modificación se atenga a ciertas condiciones. Según el Tribunal Constitucional, sobre los órganos judiciales "no pesa la exigencia de resolver siempre en los mismos términos sobre supuestos que se pretenden iguales". La primera de ellas es la motivación: la modificación por parte de un órgano judicial de su línea jurisprudencial ha de realizarse con una adecuada fundamentación que excluya la arbitrariedad. No obstante, el Tribunal Constitucional ha admitido las motivaciones implícitas siempre y cuando de la propia lógica interna de la resolución, o de datos externos a ella, pueda inferirse con relativa seguridad que el cambio objetivamente perceptible es consciente, se ha adoptado de forma reflexiva y no es fruto de un voluntarismo selectivo y, por ello mismo, arbitrario (SSTC 49/1985, 166/1985, 58/1986 y 66/1987).

La segunda condición es que la nueva interpretación se presente como solución genérica, aplicable a la totalidad de casos semejantes que puedan presentarse en el futuro, y no como fruto de un mero voluntarismo selectivo frente a casos anteriores resueltos de modo diverso ${ }^{6}$.

Para finalizar, indicar que aunque las anteriores referencias se refieran exclusivamente a los órganos judiciales, son igualmente válidas para los órganos administrativos en su función de aplicación de las normas jurídicas. No obstante, es necesario hacer algunas observaciones al cambio de criterio de los mismos. Así, no cabrá estimar vulnerado el principio de igualdad cuando el cambio se produzca motivado por la necesidad de adecuarse a la interpretación que hacen los Tribunales de Justicia. Y tampoco cuando sea confirmado por resoluciones de los Tribunales, que son los competentes para realizar la interpretación y aplicación de la legalidad ordinaria, sin que el precedente administrativo no sancionado pueda prevalecer frente al que ha obtenido la sanción judicial (SSTC 73/1988, 130/1988 y 47/1989). En cualquier caso, al igual que ocurre respecto a los órganos judiciales, el principio igualdad sólo se aplica a las decisiones que tengan su origen en un mismo órgano o entidad, esto es, a las resoluciones adoptadas dentro de un mismo ámbito de organización y dirección, y en virtud de un mismo poder de decisión (STC 47/1989).

\section{EL MANDATO ANTIDISCRIMINATORIO}

Ante todo, se ha de precisar que la distinción que proponemos entre el mandato antidiscriminatorio del segundo inciso del art. $14 \mathrm{CE}$ : “(..) sin que pueda prevalecer discriminación alguna por razón de nacimiento, raza, sexo, religión, 
opinión o cualquier otra condición o circunstancia personal o social", frente al principio genérico de igualdad del primer inciso del precepto, implica un concepto restringido de discriminación según el cual esta no equivale a una simple desigualdad injustificada o irrazonable, sino a un tipo especial de desigualdad caracterizada por su naturaleza especialmente odiosa, al atentar contra la dignidad humana. Tal distinción es fruto de una evolución en la jurisprudencia del Tribunal Constitucional que ha ido concretando los efectos principales de la misma7:

- Mientras que la cláusula general de igualdad solo es alegable ante los poderes públicos, el mandato antidiscriminatorio también es directamente aplicable en las relaciones entre sujetos privados: "el respeto de la igualdad ante la Ley se impone a los órganos del poder público, pero no a los sujetos privados, cuya autonomía está limitada sólo por la prohibición de incurrir en discriminaciones contrarias al orden público constitucional, como son, entre otras, las que expresamente se indican en el art. 14 CE" (STC 108/1989, FJ 1).

- La modulación de las reglas de la carga de la prueba en los procesos laborales, de forma que, generalizando, cuando la parte actora alegue discriminación y aporte indicios fundados de su existencia, corresponderá a la parte demandada probar la razonabilidad y proporcionalidad de la medida adoptada y su carácter absolutamente ajeno a todo propósito atentatorio de los derechos fundamentales. No se trata de una auténtica inversión dela carga de la prueba en sentido técnico jurídico estricto, sino de una modulación de la regla general, de una nueva distribución de la carga de la prueba entre los litigantes que tiende a aligerar, aliviar, facilitar, por utilizar algunas de las varias expresiones de la jurisprudencia constitucional y de la doctrina científica, la carga de la prueba del demandante, mientras se sobrecarga la del demandado ${ }^{8}$. Actualmente, así se recoge expresamente en el art. 96.1 de la Ley 36/2011, de 10 de octubre, reguladora de la Jurisdicción Social9. Y más allá del orden jurisdiccional social, en el art. 77 del Real Decreto Legislativo 1/2013, de 29 de noviembre, por el que se aprueba el Texto Refundido de la Ley General de las personas con discapacidad y de su inclusión social ${ }^{10}$, cuando se alegue discriminación por razón de discapacidad. Y en similares términos, cuando se alegue discriminación por razón de sexo, en el art. 13 de la Ley Orgánica 3/2007, para la Igualdad Efectiva de Mujeres y Hombres ${ }^{11}$, en el art. 217.5 de la Ley 1/2000, de 7 de enero, de Enjuiciamiento Civil, y en el art. 60.7 de la Ley 29/1998, de 13 de julio, reguladora de la Jurisdicción Contencioso-Administrativa ${ }^{12}$. El Proyecto de Ley Integral para la Igualdad de Trato y la No Discriminación, de 10 de junio de 2011 (que caducó como consecuencia de la disolución anticipada de las Cámaras), con vocación de convertirse en el mínimo común denominador normativo en materia de definiciones fundamentales del derecho antidiscriminatorio español y sus garantías básicas, en un intento de uniformizar la regulación al respecto establecía tal norma general en su art. 28 , excluyendo en todo caso a los 
procesos penales, a los procedimientos administrativos sancionadores y a las medidas adoptadas y los procedimientos tramitados al amparo de las normas de organización, convivencia y disciplina de los centros docentes ${ }^{13}$. Posteriormente tal proyecto fue presentado como Proposición de Ley por el Grupo Parlamentario Socialista. Finalmente fue rechazada.

- El distinto rigor aplicable a la justificación de la desigualdad. En su sentencia 81/1982, el Tribunal Constitucional es muy claro al respecto: "Y si esa carga de la demostración del carácter justificado de la diferenciación es obvia en todos aquellos casos que quedan genéricamente dentro del principio general de igualdad que consagra el artículo 14 de la Constitución, tal carga se torna aún más rigurosa en aquellos otros casos en que el factor diferencial es precisamente uno de los típicos que el artículo 14 concreta para vetar que puedan ser base de diferenciación (...)".

- La especial sensibilidad hacia las formas indirectas o encubiertas de discriminación. Cabe citar en este sentido la STC 242/1988, que considera discriminatoria la condición de ser "cabeza de familia" para reincorporarse al trabajo, y también las 145/1991 y 58/1994, en relación con diferencias salariales entre categorías con distinta denominación para hombres y mujeres, pero similar carga.

- La titularidad también para los extranjeros de este derecho, aun a pesar de la literalidad del art. 14, que sólo se refiere a los españoles, y ello por tratarse de un derecho imprescindible para la garantía de la dignidad humana y perteneciente a la persona en cuanto tal y no como ciudadano. Y sin que el legislador pueda establecer distinciones respecto a los españoles, ni entre extranjeros regulares o irregulares (SSTC 137/2000 y 236/2007).

\section{EL PRINCIPIO DE IGUALDAD MATERIAL Y LAS MEDIDAS DE ACCIÓN POSITIVA: ACCIONES POSITIVAS MODERADAS Y MEDIDAS DE DISCRIMINACIÓN INVERSA}

En el entorno europeo, la primera Constitución que recoge explícitamente esta idea de la materialidad del principio de igualdad es la Constitución italiana de 1947, en el segundo párrafo de su art. 3. El art. 3 de la Constitución italiana establece: "Todos los ciudadanos tienen la misma dignidad social y son iguales ante la ley, sin distinción de sexo, raza, lengua, religión, opiniones políticas ni circunstancias personales y sociales. Constituye obligación de la República suprimir los obstáculos de orden económico y social que, limitando de hecho la libertad y la igualdad de los ciudadanos, impiden el pleno desarrollo de la persona humana y la participación efectiva de todos los trabajadores en la organización política, económica y social del país”.

La Constitución española de 1978 incluye un precepto similar. Se trata del art. 9.2 que, según la interpretación más común consagra el principio de 
igualdad material, frente al principio de igualdad formal del art. 14. Establece que: "Corresponde a los poderes públicos promover las condiciones para que la libertad y la igualdad del individuo y de los grupos en que se integra sean reales y efectivas; remover los obstáculos que impidan o dificulten su plenitud y facilitar la participación de todos los ciudadanos en la vida política, económica, cultural y social".

Cabe observar, en primer lugar, que estos dos preceptos que reconocen con carácter general el principio de igualdad en la Constitución española se encuentran en distinto título, y ello condiciona las garantías de que goza cada uno de ellos. En efecto, el artículo 14 está ubicado en el Título I, relativo a los derechos y deberes fundamentales, y goza de la máxima protección constitucional, que incluye el recurso de amparo constitucional, mientras que el art. 9.2 está situado en el Título Preliminar, cuya dimensión normativa es más débil.

Sobre la eficacia jurídica del art. 9.2 se ha dicho que su estructura normativa como norma de programación final impide su consideración como norma fundamentadora de derechos subjetivos de los ciudadanos esgrimibles ante los tribunales. Su eficacia se traduciría en su utilización como criterio interpretativo del resto del ordenamiento, incluido por supuesto el art. 14 de la Constitución, y también se ha llegado a apuntar, aunque esto es más discutible, en parámetro de la constitucionalidad de las leyes ${ }^{14}$.

En la mayor parte de sentencias que se refieren al art. 9.2 CE, el Tribunal Constitucional ha interpretado dicho precepto como un correctivo de la igualdad formal del art 14, insistiendo en la necesidad de que el Legislador no trate a todos los individuos de la misma forma, sino que sea capaz de tratar de forma diferente aquellas situaciones que son distintas en la vida real. Así, ha afirmado en varias sentencias que "lo proclamado en el art. 9.2 puede exigir un mínimo de desigualdad formal para progresar hacia la consecución de la igualdad sustancial" (fundamentalmente las sentencias 114/1983 de 6 de diciembre, 98/1985, de 29 de julio y 19/1988, de 16 de febrero). De este modo, puede decirse que el Tribunal Constitucional español ha utilizado el art. 9.2 de la Constitución con una funcionalidad justificadora de tratos normativos favorables a ciertos sectores sociales tradicionalmente discriminados, impidiendo con ello que contradigan el principio de igualdad formal del art. $14^{15}$.

Sin embargo, existe otralínea en la jurisprudencia del Tribunal Constitucional español sobre el principio de igualdad que justifica los supuestos de trato normativo diferenciado y favorable a ciertos sectores sociales tradicionalmente discriminados, con la finalidad última de conseguir la igualdad real, basándose únicamente en el art. $14 \mathrm{CE}$. Sosteniendo un concepto más amplio del principio general de igualdad de este precepto, a él pueden reconducirse aquellos supuestos que antes eran resueltos en base al art. 9.2. Así se hace en las Sentencias 65/1983, de 21 de julio: 25/1989, de 3 de febrero; 180/1991, de 23 de septiembre y, especialmente, en la Sentencia 19/1989, de 31 de enero donde se afirma: "la virtualidad del art. 14 de la Constitución no se agota en la cláusula general de igualdad que inicia su contenido sino que también 
persigue la interdicción de determinadas diferencias, históricamente muy arraigadas, que, tanto por la acción de los poderes públicos como por la práctica social, han situado a amplios sectores de la población en posiciones no sólo desventajosas, sino abiertamente contrarias a la dignidad de la persona que reconoce el art. 10 de la Constitución. De ahí que, en principio, no puedan considerarse lesivas del principio de igualdad, aun cuando establezcan un trato más favorable, las medidas que tengan por objeto compensar la situación de desventaja de determinados grupos sociales...."

Esta interpretación amplia del principio de igualdad del art. 14 de la Constitución como justificador también de las diferencias de trato que persiguen corregir las desigualdades de hecho es sostenida también por algunos autores en la doctrina española que ponen de manifiesto la innecesariedad de la dicotomía igualdad formal-igualdad material, desde el momento en que el principio general de igualdad no impide toda diferencia de trato, sino sólo aquella que carece de una justificación objetiva y razonable. Y, obviamente, tal finalidad de equiparación de ciertos colectivos discriminados sí posee una justificación objetiva y razonable en un Estado que se proclama "social y democrático de Derecho"16.

A la vista de lo anteriormente argumentado cabe preguntarse si realmente era necesario el art. 9.2 de la Constitución. Como señala TORRES DEL MORAL ${ }^{17}$, la igualdad real y efectiva no está enfrentada con la igualdad formal, sino que es su proyección más plausible en un Estado social y democrático de Derecho. En éste, la igualdad no puede ser únicamente formal, sino también real. Desde la óptica de un Estado Social contemporáneo, no es indiferente la situación real en que se encuentran los ciudadanos a la hora de crear y aplicar la ley. El Estado Social asume necesariamente una función redistributiva y compensadora de las diferencias sociales con el objetivo, entre otros, de garantizar un bienestar material generalizado. Por tanto, compartimos la opinión de este autor de que el art. 9.2 no era necesario, en el sentido de absolutamente imprescindible para fundamentar la igualdad real o material, pero tampoco ocioso, pues facilita expresamente la cobertura jurídica de las denominadas acciones positivas de los poderes públicos en pro de la igualdad material (la igualdad real y efectiva), haciendo prescindibles interpretaciones más prolijas.

Lo que no se encuentra en la jurisprudencia constitucional española es el reconocimiento del principio de igualdad material (art. 9.2) como fundamentador de un derecho subjetivo a un trato jurídico desigual. Es más, en su Sentencia 86/1985, de 10 de julio, el Tribunal Constitucional español concluye que el art. 14 de la Constitución no reconoce un "derecho a la singularización normativa". Es decir, del art. 14 no cabe derivar un derecho subjetivo jurisdiccionalmente protegido a recibir un trato diferente y favorable en determinadas circunstancias, del mismo modo que sí existe un derecho subjetivo a no ser discriminado fundado en dicho precepto. La determinación de en qué casos procede aplicar un trato jurídico diferente y favorable a determinados colectivos corresponde al Legislador $^{18}$. 
Como ya hemos adelantado, directamente relacionado con el principio de igualdad material se encuentra la temática relativa a las medidas de "acción positiva", que encuentran su fundamentación en el mismo. Éstas, en sus diversas manifestaciones, incorporan al continente europeo el llamado Derecho antidiscriminatorio anglosajón y, en especial, el Norteamericano.

Podríamos definirlas como "todas aquellas medidas, diversas en sus manifestaciones, que tienen como destinatarios directos a personas que están o han estado discriminadas o que se hallan en una situación de desventaja estructural como consecuencia de su pertenencia a un cierto colectivo, pertenencia determinada por la posesión de algún rasgo completamente inmutable e íntimamente ligado, en tanto que definitorio de su identidad, a su dignidad como seres humanos, y que persiguen poner fin a esa situación de desventaja estructural, reducir los niveles de desigualdad entre dichos colectivos (y sus miembros) y el resto de la sociedad, y alcanzar mayores cotas de igualdad real dentro de la comunidad" 19 .

En un esfuerzo de generalización, admiten dos grandes modalidades: las acciones positivas moderadas y las medidas de discriminación inversa, cuya problemática constitucional difiere. Las primeras inciden en la igualdad de oportunidades, no de resultados. Las segundas, mucho más incisivas, provocan un daño directo en los miembros de grupos no beneficiados.

Las más pacíficamente aceptadas y cuyo uso se encuentra generalizado en toda Europa son las denominadas medidas de acción positiva moderada. Son las menos incisivas, y se concretan en "medidas de incentivación" que, sin asegurar resultados, se dirigen genéricamente a incrementar las oportunidades competitivas de personas tradicionalmente discriminadas por su pertenencia a colectivos desfavorecidos. Dentro de esta categoría se incluirían medidas que favorezcan su acceso a cursos de formación y reciclaje profesional, sobre todo en los sectores en que están infrarrepresentados; incentivos indirectos a su contratación, como es el caso de las bonificaciones en el pago de las cuotas empresariales a la Seguridad Social; incentivos directos a tales contrataciones, como son las subvenciones económicas a la contratación; ciertas medidas de fomento de la promoción profesional de estos colectivos y de su acceso a puestos de responsabilidad y toma de decisiones, tanto en instituciones públicas como en empresas públicas y privadas, etc.

$\mathrm{Si}$ son proporcionales, no plantean problemas de constitucionalidad, porque cumplirían los criterios vistos en relación al principio de igualdad en la ley que evitaban las diferencias arbitrarias del legislador: desigualdad de los supuestos de hecho; finalidad de la medida diferenciadora constitucionalmente aceptable; congruencia entre los medios y el fin perseguido, y proporcionalidad entre estos factores, de forma tal que la relación entre medios y fines esté suficientemente ponderada. Por otra parte, hay igualmente coincidencia en señalar que las mismas deberán tener carácter temporal, de tal forma que sólo será admisible su vigencia mientras perdure la desigual real del colectivo o grupo en cuestión. De otro modo, 
las ventajas que incorporan se convertirían en privilegios injustificables por inflingir sacrificios innecesarios al grupo o colectivo no favorecido por las mismas.

El Tribunal Constitucional se ha encargado de diferenciarlas de la categoría de las acciones protectoras, por ejemplo, a favor de la mujer. Estas últimas, como las acciones positivas moderadas, son normas que recogen determinadas ventajas para la mujer. Sin embargo, su finalidad no es la superación de la desigualdad, sino asumir el rol inferior de la mujer y favorecer su perpetuación con medidas paternalistas. Fueron muy frecuentes en nuestro país en la época anterior a la democracia, y aunque no tienen cabida en nuestro ordenamiento jurídico actual, la mayoría de ellas no fueron derogadas expresamente con la aprobación de la Constitución Española de 1978, permaneciendo en la normativa laboral y de Seguridad Social. Por tanto, comenzaron a plantearse por varones recursos contra las mismas.

Las medidas de discriminación inversa son la manifestación más extrema de las políticas antidiscriminatorias. No se conforman con introducir una desigualdad de trato como medio para promover la igualdad real, sino que, además, esa desigualdad provoca un daño directo en los miembros no beneficiados por la medida antidiscriminatoria, al incidir directamente en los procesos selectivos para acceder a bienes escasos de la sociedad (puestos de trabajo, plazas universitarias, candidaturas electorales, contratos con la Administración, etc).

Las medidas de discriminación inversa en sentido amplio revisten básicamente las siguientes modalidades ${ }^{20}$ :

- Las que conceden al miembro del colectivo tradicionalmente marginado una puntuación extra por su condición de tal, que se sumaría a la puntuación asignada a los méritos $\mathrm{u}$ otras condiciones valoradas en el proceso de selección. El bien escaso en cuestión no se le concede automáticamente, pero su candidatura es especialmente tenida en consideración porque pasa a ocupar una posición superior en el ranking de candidatos, al valorase, adicionalmente, su condición de miembro de un colectivo tradicionalmente marginado.

- Las que podríamos denominar “medidas de desempate", que en los procesos selectivos otorgan preferencia al miembro del colectivo discriminado con la misma capacitación o nivel de cualificación que otro candidato, si en el sector en cuestión los miembros de dicho grupo están infarrepresentados. Es decir, no se concede el bien escaso a nadie que, aun perteneciendo al grupo tradicionalmente marginado, reúna menos méritos que los otros aspirantes. Este tipo de medidas tiene la ventaja de que no vulnera la selección meritocrática, al garantizar que el candidato finalmente elegido está entre los más cualificados, pero tiene el inconveniente, si funciona con carácter automático, de obviar por completo las circunstancias personales del preterido que no pertenece al colectivo desfavorecido, cuando puede haber tenido que superar obstáculos más graves que el finalmente 
seleccionado en atención en última instancia a su sexo, etnia, etc. Las "cláusulas de apertura", como la analizada en la sentencia Marschall del Tribunal de Justicia de las Comunidades Europeas (11 de noviembre de 1997), corrigen este defecto (cláusula de apertura de que, en todo caso, las candidaturas serán objeto de una apreciación objetiva de conjunto que tenga en cuenta también las circunstancias individuales de los candidatos, de forma tal que podrá ignorarse la preferencia establecida en función de estas últimas).

- El tercer grupo de medidas, que podríamos denominar de "discriminación inversa en sentido estricto", no exigen necesariamente a los miembros del grupo tradicionalmente discriminado la misma cualificación que a los otros, sino que se da preferencia, por ejemplo, a la contratación o promoción del miembro del colectivo infrarrepresentado pese a que su cualificación sea inferior, aunque lo que sí se suele exigir en todo caso es una cualificación mínima necesaria para desempeñar la tarea de que se trate.

También habría que incluir en esta última categoría las que reservan cuotas para ser cubiertas por miembros de los colectivos discriminados en la adjudicación de recursos o bienes escasos socialmente valiosos donde no rigen procesos selectivos objetivos y transparentes de valoración meritocrática (cuotas electorales para mujeres, puestos directivos de elección discrecional, etc); o las que consisten en cuotas en procesos de adjudicación que no se rigen por el principio de mérito y capacidad (cuotas para viviendas de protección oficial, etc.).

La constitucionalidad de las medidas de discriminación inversa es más discutida y, no es posible ofrecer un pronunciamiento general al respecto, pues dependerá de las características concretas de dicha medida y de los distintos derechos e intereses en conflicto. En definitiva, habrá que ponderar caso por caso ${ }^{21}$.

En todo caso, al menos respecto de las que hemos denominado medidas de discriminación inversa en sentido estricto, parece que las mismas no debieran implementarse cuando sea posible llegar a los mismos objetivos de equiparación de ese colectivo con los restantes, en un tiempo razonable, a través de medidas menos extremas de acción positiva. $\mathrm{Y}$ en todo caso debe exigirse su proporcionalidad, de forma que no generen un excesivo desequilibrio entre las cargas que entraña para la sociedad o terceros y los bienes que reporta al colectivo beneficiado. Por ejemplo, en el ámbito de la Administración Pública no respetaría el principio de proporcionalidad la adjudicación de un empleo a quien no esté en absoluto cualificado para desempeñarlo, o excluir sistemáticamente, aunque sea de forma temporal, a los miembros del colectivo dominante del acceso a ciertos empleos o categorías profesionales, pues incluso aunque con ello se pretenda promover la igualdad real y efectiva de otros seres humanos tradicionalmente marginados, no se pueden reducir las oportunidades de los miembros del colectivo dominante a unos 
niveles inferiores a aquellos en que estarían de haberse logrado ya en esa sociedad la plena igualdad de oportunidades para todos los grupos.

También parece razonable defender la transitoriedad temporal de dichas medidas, limitadas al tiempo necesario para lograr la igualación entre los sectores de población en comparación.

En España, el Tribunal Constitucional sólo se ha pronunciado expresamente sobre las discriminaciones inversas en sentido estricto, declarándolas constitucionales, en dos ocasiones. En primer lugar, en la STC 269/1994, que resolvió un caso en el que además del principio de igualdad entraban en juego los criterios de mérito y capacidad exigidos en los arts. 23.2 y 103.3 de la Constitución para el acceso a la función pública. En esta sentencia, la medida que se ponía en cuestión estaba contenida en una Orden donde se desarrollaban las bases de un concurso-oposición para ocupar plaza de Administrador General de la Comunidad Autónoma de Canarias. Esta Orden, en cumplimiento del mandato contenido en la Ley de la Función Pública de Canaria, que establecía la obligatoriedad de reservar plazas para personas con discapacidades físicas, psíquicas o sensoriales iguales o superiores al 33\% hasta alcanzar una cuota del $3 \%$ en el funcionariado, reservaba seis plazas para miembros de tal colectivo siempre que superasen las pruebas selectivas. Una mujer sin discapacidades que perdió la plaza, pese a tener una puntuación mayor frente a un discapacitado con sordera, recurre estas bases por considerarlas contrarias al artículo 14 y 23.2 CE. El Tribunal Constitucional, sugiriendo que cabe integrar la discapacidad en la cláusula abierta del artículo $14 \mathrm{CE}$ ("sin que pueda prevalecer discriminación por cualquier otra condición o circunstancia personal o social"), considera que el establecimiento de medidas favorecedoras como la recurrida no sólo no vulneran el artículo $14 \mathrm{CE}$, sino que constituyen un desarrollo del mandato de igualdad sustancial contenido en el art. 9.2 CE, y del de integración de las personas con discapacidad del art. 49. Esta sentencia no suscitará prácticamente crítica alguna en la doctrina, por las condiciones extremadamente difíciles de tal colectivo para su acceso al mercado laboral.

En segundo lugar, en la Sentencia 12/2008, de 29 de enero de 2008 el Tribunal Constitucional aborda los recursos (uno por parte del Partido Popular y una cuestión de inconstitucionalidad) planteados contra la Ley Orgánica 3/2007, de 22 de marzo, para la igualdad efectiva de mujeres y hombres, que incluye una reforma de la Ley Orgánica de Régimen Electoral General (LOREG) en virtud de la cual las candidaturas que se presenten para las elecciones al Congreso, municipales, elecciones europeas y autonómicas deberán tener una composición equilibrada de mujeres y hombres, de forma que en el conjunto de la lista los candidatos de cada uno de los sexos supongan como mínimo el cuarenta por ciento. Obligándose también a mantener la proporción mínima del cuarenta por ciento en cada tramo de cinco puestos. Igualmente, cuando las candidaturas al Senado se agrupen en listas, tales listas deberán tener una composición equilibrada de mujeres y hombres, de forma que la proporción de unas y otros sea lo más 
cercana posible al equilibrio numérico. Dichas previsiones, sin embargo, no serán exigibles en las candidaturas que se presenten en municipios con un número de residentes igual o inferior a 5000 habitantes.

El Tribunal Constitucional fue rebatiendo cada una de las alegaciones presentadas, pronunciándose finalmente a favor de su constitucionalidad:

- La democracia paritaria no supone la quiebra de ninguno de los pilares del sistema democrático, ni puede ser equiparada a las formas de democracia corporativa. En primer lugar, porque el cuerpo electoral no se divide en función del sexo; en segundo lugar, porque no se impone a los electores votar sólo a los candidatos de su propio sexo y, finalmente, porque los hombres y mujeres que resulten elegidos representarán al conjunto de los ciudadanos y no los intereses de un grupo sexual determinado.

- Por lo que respecta a la argumentación de la posible vulneración del principio de la libertad de actuación de los partidos políticos reconocido en el art. $6^{\circ} \mathrm{CE}$ en relación con el art. $22.1^{\circ}$ donde se reconoce el derecho de asociación, el Tribunal arguye que la libertad de presentación de candidaturas por los partidos no es ni puede ser absoluta, pues como el resto de actividades de éstos, está sometida, según establece el art. $6 \mathrm{CE}$ a la Constitución y a la ley. Ya con anterioridad el legislador (LOREG), atendiendo a otros valores y bienes constitucionalmente protegidos, limitó esa libertad imponiéndoles determinadas condiciones para la confección de las candidaturas (referidas a la elegibilidad de los candidatos, a la residencia en algunos supuestos, o incluso a que tales candidaturas hayan de serlo mediante listas cerradas y bloqueadas). Esta nueva limitación del equilibrio por razón de sexo no es pues, la única, ni carece, según el Tribunal Constitucional, de fundamento constitucional. En concreto, argumenta que resulta perfectamente constitucional por ser legítima su finalidad, y por razonablemente instrumentada. Así, en primer lugar, estima plenamente legítimo el fin de la consecución de una igualdad efectiva en el terreno de la participación política para ambos sexos (arts. $9.2,14$ y 23). Y, en segundo lugar, considera la medida proporcionada al fin perseguido, al ser equivalente el $n^{\circ}$ de hombres y mujeres en el cuerpo electoral, contemplándose además excepciones para las poblaciones de menos de 5000 habitantes.

- Tampoco aprecia una posible vulneración de la libertad ideológica de los partidos políticos ni de su libertad de expresión [arts. 16.1 y 20.1 a)], pues estima que con esta medida no se impide la existencia de partidos con una ideología contraria a la igualdad efectiva entre los ciudadanos. Como es conocido, abundante jurisprudencia del Tribunal Constitucional sostiene que en nuestro sistema no tiene cabida un modelo de "democracia militante", que imponga la adhesión positiva al ordenamiento, y en primer lugar a la Constitución. Por consiguiente, para el Alto Tribunal, el 
requisito de que las formaciones políticas que pretendan participar en los procesos electorales tengan que incluir necesariamente candidatos de uno y otro sexo en las proporciones señaladas no implica la exigencia de que esas mismas formaciones políticas participen de los valores sobre los que se sustenta la llamada democracia paritaria. Textualmente afirma: "no se impide la existencia de formaciones políticas que defiendan activamente la primacía de las personas de un determinado sexo, o que propugnen postulados que pudiéramos denominar "machistas o "feministas". Lo que exige la disposición adicional que nos ocupa es que cuando se pretenda defender esas tesis accediendo a los cargos públicos electivos se haga partiendo de candidaturas en las que se integran personas de uno y otro sexo". "Cierto que un ideario feminista radical que pretenda el predominio femenino no podrá ser constitucionalmente prohibido, pero tampoco podrá pretender sustraerse al mandato constitucional de la igualdad formal (art. $14 \mathrm{CE}$ ) ni a la normas dictadas por el legislador para hacer efectiva la igualdad material tal y como establece el art. 9.2".

- En relación a posibles vulneraciones del derecho de sufragio activo (23.1) y pasivo (23.2) las considera inexistentes, pues la medida en cuestión tiene por únicos destinatarios directos a quienes pueden presentar candidaturas, esto es, a los partidos, federaciones y coaliciones de partidos y a las agrupaciones de electores, entidades jurídicas que no son sujetos de los derechos de sufragio activo y pasivo, cuya vulneración se denuncia. Por otra parte, añade que el derecho de sufragio pasivo del art. 23.2 CE no incorpora entre sus contenidos un pretendido derecho fundamental a ser propuesto o presentado, por las formaciones políticas, como candidato en unas elecciones. Como tampoco el derecho de sufragio activo del art. 23.1 $\mathrm{CE}$ incluye la facultad de otorgar la condición de candidato a quien no fue propuesto como tal por las formaciones políticas.

- Por último, señalar que desde la perspectiva del art. 14, el Alto Tribunal viene a sostener que cualquiera que sea la caracterización que merezca la reforma de la LOREG, lo cierto es que no se articula como una clásica medida de discriminación positiva que actúe solo en beneficio de un determinado grupo escasamente representado. La norma, desde el punto de vista de su construcción abstracta, es escrupulosamente respetuosa con el principio de igualdad, dado su carácter bidireccional. Otra cosa será que por la tradicional inferior presencia de las mujeres en las candidaturas de los partidos políticos, su aplicación práctica beneficie inicialmente a las mujeres, corrigiendo una situación de desigualdad de origen. Reiterando que, desde esta perspectiva, la medida tiene un fin lícito y legítimo: la superación de la desigualdad histórica de la participación política de las mujeres; resultando racional y proporcionada al fin perseguido, por ser cuantitativamente equivalente el número de hombres y mujeres en el cuerpo electoral ${ }^{22}$. 


\section{NOTAS}

1 RUIZ MIGUEL, A.: "La igualdad en la jurisprudencia del Tribunal Constitucional", en AA.VV.: El principio de igualdad, Luis García San Miguel (editor), Dykinson, Madrid, 2000, pág. 160.

2 El Tribunal Constitucional ha admitido la eficacia inmediata entre particulares del principio de igualdad exclusivamente en su vertiente de mandato antidiscriminatorio, y ello porque en virtud del principio de la autonomía de la voluntad, amparado también constitucionalmente en los artículos 1.1, 10.1 y 38, entre otros, los particulares son libres, dentro del respeto a las leyes, la moral y el orden público (art. 1255 CC), para gestionar sus intereses. Para el Tribunal Constitucional, la obligación de respetar el principio constitucional de igualdad ante la ley "se impone a los órganos del poder público, pero no a los sujetos privados, cuya autonomía está limitada sólo por la prohibición de incurrir en discriminaciones contrarias al orden público constitucional, como son, entre otras, las que expresamente se indican el art. 14 CE" (STC 108/1989, FJ 1). Fuera de estos supuestos, los tratos desiguales de los particulares solo tendrán relevancia jurídica si existe "un principio jurídico del que deriva la necesidad de igualdad de trato entre los desigualmente tratados", principio que podrá estar establecido bien en otra disposición constitucional, bien en una Ley o en una norma escrita de rango inferior, en la costumbre o en los principios generales del derecho (SSTC 59/1982 y 34/1984, entre otras).

3 Vid. más ampliamente al respecto, GAVARA DE CARA, J.C.: Contenido y función del término de comparación en la aplicación del principio de igualdad, Aranzadi, Navarra, 2005.

4 GARCÍA MORILlO, J.: Derecho Constitucional. Volumen I: El ordenamiento constitucional. Derechos y deberes de los ciudadanos, AA.VV., Tirant Lo Blanch, 9. a ed., Valencia, 2013, pág. 166.

5 Vid. más ampliamente sobre la igualdad en la ley la primera parte de la monografía de GARRIDO GÓMEZ, M. ${ }^{a}$ I.: La igualdad en el contenido y en la aplicación de la ley, Dykinson, Madrid, 2009.

6 Una completa monografía sobre esta dimensión de la igualdad nos la ofrece CABAÑAS GARCÍA, J.C.: El derecho a la igualdad en la aplicación judicial de la ley, Aranzadi, Navarra, 2009. Vid. también OLLERO TASSARA, A.: Igualdad en la aplicación de la ley y precedente judicial, Centro de Estudios Políticos y Constitucionales, Madrid, 2005.

7 Vid. RUIZ MIGUEL, A.: "La igualdad en la jurisprudencia del Tribunal Constitucional", cit., págs. 168 a 184.

8 LOUSADA AROCHENA, J.F.: "La prueba de la discriminación y del acoso sexual y moral en el proceso laboral”, Cuadernos de derecho judicial, No 7, 2005, pág. 324.

9 "1. En aquellos procesos en que de las alegaciones de parte actora se deduzca la existencia de indicios fundados de discriminación por razón de sexo, orientación o identidad sexual, origen racial o étnico, religión o convicciones, discapacidad, edad, acoso y en cualquier otro supuesto de vulneración de un derecho fundamental o libertad pública, corresponderá al demandado la aportación de una justificación objetiva y razonable, suficientemente probada, de las medidas adoptadas y de su proporcionalidad".

10 "1. En aquellos procesos jurisdiccionales en que de las alegaciones de la parte actora se deduzca la existencia de indicios fundados de discriminación por motivo de o por razón de discapacidad, corresponderá a la parte demandada la aportación de una justificación objetiva y razonable, suficientemente probada, de la conducta y de las medidas adoptadas y de su proporcionalidad. Cuando en el proceso jurisdiccional se haya suscitado una cuestión de discriminación por motivo de o por razón de discapacidad, el Juez o Tribunal, a instancia de parte, podrá recabar informe o dictamen de los organismos públicos competentes. 2. Lo establecido en el apartado anterior no es de aplicación a los procesos penales ni a los contencioso-administrativos interpuestos contra resoluciones sancionadoras".

11 "1. De acuerdo con las Leyes procesales, en aquellos procedimientos en los que las alegaciones de la parte actora se fundamenten en actuaciones discriminatorias, por razón de sexo, corresponderá 
a la persona demandada probar la ausencia de discriminación en las medidas adoptadas y su proporcionalidad. A los efectos de lo dispuesto en el párrafo anterior, el órgano judicial, a instancia de parte, podrá recabar, si lo estimase útil y pertinente, informe o dictamen de los organismos públicos competentes. 2. Lo establecido en el apartado anterior no será de aplicación a los procesos penales".

12 Redacción común a ambos: "De acuerdo con las leyes procesales, en aquellos procedimientos en los que las alegaciones de la parte actora se fundamenten en actuaciones discriminatorias por razón del sexo, corresponderá al demandado probar la ausencia de discriminación en las medidas adoptadas y de su proporcionalidad. A los efectos de lo dispuesto en el párrafo anterior, el órgano judicial, a instancia de parte, podrá recabar, si lo estimase útil y pertinente, informe o dictamen de los organismos públicos competentes".

13 "1. De acuerdo con lo previsto en las leyes procesales y reguladoras de los procedimientos administrativos, cuando la parte actora o el interesado alegue discriminación y aporte indicios fundados sobre su existencia, corresponderá a la parte demandada o a quien se impute la situación discriminatoria la aportación de una justificación objetiva y razonable, suficientemente probada, de las medidas adoptadas y de su proporcionalidad. 2. A los efectos de lo dispuesto en el párrafo primero, el órgano judicial o administrativo, de oficio o a instancia de parte, podrá recabar informe de los organismos públicos competentes en materia de igualdad. 3. Lo establecido en el apartado primero no será de aplicación a los procesos penales ni a los procedimientos administrativos sancionadores, ni a las medidas adoptadas y los procedimientos tramitados al amparo de las normas de organización, convivencia y disciplina de los centros docentes".

14 CARMONA CUENCA, E.: "Normas constitucionales de contenido social: delimitación y problemática de su eficacia jurídica”, Revista de Estudios Políticos, n. ${ }^{\circ} 76,1992$. También MONTILLA MARTOS, J.A.: "El mandato constitucional de promoción de la igualdad real y efectiva en la jurisprudencia constitucional. Su integración con el principio de igualdad”, en AA.VV., Estudios de Derecho Público. Homenaje a Juan José Ruiz-Rico, Vol. I, Tecnos, Madrid, 1997, fundamentalmente, págs. 462-463.

15 CARMONA CUENCA, E.: "El principio de igualdad material en la Constitución Europea", Revista del Foro Constitucional Iberoamericano, nº 8, 2004, pág. 7.

16 Ibídem. También BILBAO UBILLOS, J.M. y REY MARTÍNEZ, F.: "El principio constitucional de igualdad en la jurisprudencia española”, en AA.VV. (M. Carbonell Comp.), El principio constitucional de igualdad, Comisión Nacional de los Derechos Humanos, México, 2003, pág. 109.

17 TORRES DEL MORAL, A.: “¿Qué igualdad?, Revista de Derecho Político, n 44, 1998, pág. 97.

18 CARMONA CUENCA, E.: “El principio de igualdad material..., cit., pág. 8.

19 MARTÍN VIDA, M. ${ }^{a}$ A.: Fundamento y límites constitucionales de las medidas de acción positiva, Civitas, Madrid, 2003, págs. 39-40.

20 MARTÍN VIDA, M. ${ }^{a}$ A.: Fundamento y límites constitucionales de las medidas de acción positiva, cit., págs. $47-48$.

21 GIMÉNEZ GLUCK, D.: Una manifestación polémica del principio de igualdad: Acciones positivas moderadas y medidas de discriminación inversa, Tirant Lo Blanch, Valencia, 1999, págs. 165 y ss.

22 Más ampliamente, MARTíNEZ ALARCÓN, M. ${ }^{a}$ L.: "La Ley Orgánica para la igualdad efectiva de mujeres y hombres y la sentencia del Tribunal Constitucional 12/2008, de 29 de enero", Revista de Estudios Políticos, n 142, 2008. 


\section{Resumen}

En ese texto se analiza el principio de la igualdad en la Constitución española. Así, se examina la conformación de la igualdad formal, traducida en el principio de la igualdad en la ley y en el principio de la igualdad en la aplicación de la ley. A continuación se trata del mandato antidiscriminatorio y sus efectos. Por último, se contempla, en este análisis, el principio de la igualdad material y las medidas de acción positiva que buscan hacerlas efectivas.

Palavras-clave: Constitución española. Igualdad formal. Igualdad material. Mandato antidiscriminatorio. 


\section{A IGUALDADE NA CONSTITUIÇÃO ESPANHOLA}

\section{Resumo}

O presente texto tem como objetivo analisar o princípio da igualdade na Constituição espanhola. Nesse sentido, examina-se a conformação da igualdade formal, consubstanciada no princípio da igualdade perante a lei e no princípio da igualdade na aplicação da lei. Em seguida, aborda-se o mandato antidiscriminatório e seus efeitos. Por fim, contempla-se, nesta análise, o princípio da igualdade material e as medidas de ação positiva que visam torna-la efetiva.

Palavras-chave: Constituição espanhola. Igualdade formal. Igualdade material. Mandato antidiscriminatório. 


\title{
EQUALITY IN THE SPANISH CONSTITUTION
}

\begin{abstract}
The purpose of this text is to analyze the principle of equality in the Spanish Constitution. In this sense, it examines the formation of formal equality, embodied in the principle of equality before the law and in the principle of equality in law enforcement. It then addresses the anti-discrimination mandate and its effects. Finally, we contemplate, in this analysis, the principle of material equality and positive action measures aimed at making it effective.
\end{abstract}

Keywords: Spanish constitution. Formal equality Material equality. Anti-discrimination mandate. 